\title{
A new cognitive evaluation battery for Down syndrome and its relevance for clinical trials
}

OPEN ACCESS

Edited by:

Chris J. Gibbons,

University of Manchester, UK

Reviewed by:

José M. Delgado-García,

University Pablo de Olavide, Spain

Robert Albert McArthur,

McArthur and Associates $\mathrm{GmbH}$,

Switzerland

Mingna Liu,

Northwestern University, USA Andre Strydom,

University College London, UK

*Correspondence:

Susana de Sola,

Centre for Genomic Regulation and

IMIM-Hospital del Mar Medical

Research Institute, Parc de Recerca

Biomédica de Barcelona, C/Doctor

Aiguader, 88, 08003 Barcelona, Spain sdesola@imim.es

Specialty section:

This article was submitted to

Psychology for Clinical Settings,

a section of the journal

Frontiers in Psychology

Received: 14 November 2014 Accepted: 12 May 2015

Published: 04 June 2015

Citation:

de Sola S, de la Torre R, Sánchez-Benavides G, Benejam B,

Cuenca-Royo A, del Hoyo L,

Rodríguez J, Catuara-Solarz S,

Sanchez-Gutierrez J, Dueñas-Espin I, Hernandez G, Peña-Casanova J, Langohr K, Videla S, Blehaut H, Farre $M$, Dierssen $M$ and The TESDAD

Study Group (2015) A new cognitive evaluation battery for Down syndrome and its relevance for clinical trials. Front. Psychol. 6:708. doi: 10.3389/fpsyg.2015.00708

\author{
Susana de Sola ${ }^{1,2 *}$, Rafael de la Torre ${ }^{1,3,4}$, Gonzalo Sánchez-Benavides ${ }^{1,5}$, \\ Bessy Benejam ${ }^{6}$, Aida Cuenca-Royo ${ }^{1,7}$, Laura del Hoyo ${ }^{1}$, Joan Rodríguez ${ }^{1}$, \\ Silvina Catuara-Solarz ${ }^{2}$, Judit Sanchez-Gutierrez ${ }^{8}$, Ivan Dueñas-Espin ${ }^{1,4}$, \\ Gimena Hernandez ${ }^{1,9}$, Jordi Peña-Casanova ${ }^{1,5}$, Klaus Langohr ${ }^{1,10}$, Sebastia Videla ${ }^{6}$, \\ Henry Blehaut ${ }^{11}$, Magi Farre ${ }^{1,12}$, Mara Dierssen ${ }^{2,13}$ and The TESDAD Study Group
}

\begin{abstract}
${ }^{1}$ Human Pharmacology and Clinical Neurosciences Research Group-Neurosciences Program, IMIM-Hospital del Mar Medical Research Institute, Barcelona, Spain, ${ }^{2}$ Cellular and Systems Neurobiology Research Group, Systems Biology Program, Centre for Genomic Regulation, Barcelona, Spain, ${ }^{3}$ Biomedical Research Centre in Physiopathology of Obesity and Nutrition (CIBEROBN), Santiago de Compostela, Spain, ${ }^{4}$ CEXS, Universitat Pompeu Fabra, Barcelona, Spain, ${ }^{5}$ Neurofunctionality of Brain and Language Group-Neurosciences Program, IMIM-Hospital del Mar Medical Research Institute, Barcelona, Spain, ${ }^{6}$ Fundació Catalana Sindrome de Down, Barcelona, Spain, ${ }^{7}$ Drug Abuse Epidemiology Research Group-Epidemiology and Public Health Program, IMIM-Hospital del Mar Medical Research Institute, Barcelona, Spain, ${ }^{8}$ Fundació Privada Espai Salut, Barcelona, Spain, ${ }^{9}$ Universitat Autónoma de Barcelona, UDIMAS, Barcelona, Spain,

${ }^{10}$ Department of Statistics and Operations Research, Universitat Politècnica de Catalunya, Barcelona, Spain, ${ }^{11}$ Fondation Jérôme Lejeune, Paris, France, ${ }^{2}$ Universitat Autònoma de Barcelona, i Hospital Universitari Germans Trias i Pujol (IGTP), Barcelona, Spain, ${ }^{13}$ Biomedical Research Centre on Rare Diseases (CIBERER), Valencia, Barcelona, Spain
\end{abstract}

The recent prospect of pharmaceutical interventions for cognitive impairment of Down syndrome (DS) has boosted a number of clinical trials in this population. However, running the trials has raised some methodological challenges and questioned the prevailing methodology used to evaluate cognitive functioning of DS individuals. This is usually achieved by comparing DS individuals to matched healthy controls of the same mental age. We propose a new tool, the TESDAD Battery that uses comparison with age-matched typically developed adults. This is an advantageous method for probing the clinical efficacy of DS therapies, allowing the interpretation and prediction of functional outcomes in clinical trials. In our DS population the TESDAD battery permitted a quantitative assessment of cognitive defects, which indicated language dysfunction and deficits in executive function, as the most important contributors to other cognitive and adaptive behavior outcomes as predictors of functional change in DS. Concretely, auditory comprehension and functional academics showed the highest potential as end-point measures of therapeutic intervention for clinical trials: the former as a cognitive key target for therapeutic intervention, and the latter as a primary functional outcome measure of clinical efficacy. Our results also emphasize the need to explore the modulating effects of IQ, gender and age on cognitive enhancing treatments. Noticeably, women performed significantly better than men of the same age and IQ in most cognitive tests, with the most consistent differences occurring in memory and executive functioning and negative trends rarely emerged on quality of life linked to the effect of age after adjusting for IQ and gender. In sum, the TESDAD battery is a useful neurocognitive tool for probing the clinical efficacy of experimental therapies in interventional studies in the 


\section{DS population suggesting that age-matched controls are advantageous for determining normalization of DS.}

Keywords: Down syndrome, TESDAD neurocognitive battery, intellectual disabilities, cognition, clinical trials as topic

\section{Introduction}

Down Syndrome (DS) is the most common genetic cause of mental retardation (Megarbane et al., 2009), with an incidence of approximately 9.65 for every 10,000 live births in Europe (Khoshnood et al., 2011). Although most of its phenotypic features are variable, both in prevalence and expression, the DS neurocognitive profile is characterized by psychomotor delay and a general, and pronounced, deficit in learning/memory, executive functions, and language abilities that shape the intellectual disability of the syndrome (Pennington et al., 2003; Rowe et al., 2006; Vicari, 2006; Iacono et al., 2010). The recent flourishing of therapy-oriented research in DS has led to an increasing number of clinical trials that require validated test batteries to test treatment efficacy and safety. Research in the field of cognitive enhancers for mental health is moving toward considering key brain networks and specific areas underlying major cognitive deficits as the main targets for therapeutic intervention, instead of focusing on broad-based neurotransmitter systems. In parallel, there is the pressing need to update the diagnostic classification schemes and the neuropsychological assessment methods according to this new neuroscience-based approach (Insel et al., 2010, 2013). Furthermore, few of the plethora of methods for cognitive assessment report clinically significant psychometric data for DS subjects, and neither do they suitably accommodate the heterogeneous range of impairments experienced by this population.

The prevailing methodology used to characterize cognitive functioning compares DS subjects, or those with other learning disabilities of genetic origin (e.g., Williams-Beuren and Fragile$\mathrm{X}$ Syndromes) or unknown etiology, to healthy controls of the same "mental age." The comparison is assumed to provide an index of global level of mental maturation (Edgin et al., 2010b; Finestack and Abbeduto, 2010; Costanzo et al., 2013a). These approaches are based on the notion that the mental maturation rate in subjects with intellectual disability differs substantially from typically developed subjects of equal chronological age, but should not differ significantly, or only in certain capacities, when matched for their "mental age" (Costanzo et al., 2013b). Whilst this perspective has been valuable for characterizing the DS cognitive phenotype, it is not useful for determining the gap in cognitive performance between DS subjects and healthy adults, which is the cognitive target we aim for in clinical trials. The few studies that have used an age-matched healthy population with standard norms have focused on the study of specific cognitive domains (e.g., language and memory processing), but have not carried out a comprehensive description of the DS profile (Næss et al., 2011).

Cognitive-enhancing therapies aim to bring cognitive and functional competence in DS closer to the standards expected for their chronological age. We propose, therefore, to use an agematched healthy control population for the systematic evaluation of the reduction, stabilization, or slowing of the cognitive and functional performance of DS with respect to therapeutic interventions. From a clinical point of view, standard norms from healthy subjects provide a feasible and valuable reference for quantifying the magnitude of cognitive improvement needed for functional changes. For example, modest cognitive gains related to experimental treatments in DS subjects, which would be considered of subclinical magnitude in typically developed adults, could imply a mild but clinically meaningful and significant impact on everyday life functioning in the DS population, which is harder to determine using mental age or mentally disabled-matched subjects as a comparison.

We have developed the TESDAD battery for clinical trials to characterize the cognitive functioning of young adults with DS, within mild to moderate-severe intellectual disability, using standard norms from age-matched typically-developed adults as a reference for this characterization. The TESDAD battery was used to explore the relative contribution of intellectual quotient (IQ), gender, and age to neurocognitive variability among DS participants, and to identify specific relationships between cognitive performance and different aspects of functional outcome that could potentially serve for expecting functional change in interventional studies.

\section{Methods}

\section{Participants}

Eighty-six young adults of both genders with DS, aged 16-34 years, with any of the three DS genetic variations (trisomy 21, mosaic, or translocation) were enrolled in the study, mainly through the Fundació Catalana de Síndrome de Down (Barcelona) a local foundation specialized in providing health care services and educational programs to participants with DS and their families.

The data reported in the present work correspond to the baseline cognitive performance of a cohort of DS participants that participated in a clinical trial NCT01699711, that has been registered in https://clinicaltrials.gov/ct2/show/NCT01699711. All participants were drug free during the baseline assessment. Upon arrival at the research center (Hospital del Mar Medical Research Institute-IMIM), participants, parents and legal guardians (in case of legal incapacitation) were informed of the ensuing protocol and they gave their written informed consent before participating. Subjects with neurological disease other than DS, relevant medical disease, unstable co-morbid mental disorder or currently taking any treatment that could interfere with cognitive function were excluded from the study. Other exclusion criteria applied to all the participants were: (i) 
having suffered from any major illness or undergoing major surgery in the last 3 months before the study; (ii) new or irregular medication in the month preceding the study; (iii) current ingestion of vitamin or catechins supplements or Non-Steroidal Anti-Inflammatory Drugs (NSAIDs) in the 2 weeks preceding the study; (iv) history of gastrointestinal, hepatic, renal, or any other problems that may alter absorption, distribution, metabolism, or excretion of the drug. Genetic variations were documented by chromosomal analysis.

\section{Test Procedure and Customized Neuropsychological Test Battery}

The study was conducted in accordance with the ethical standards laid down in the Declaration of Helsinki and approved by the local ethics committee (CEIC-Parc de Salut Mar). At study onset the participants underwent medical examinations and a brief cognitive assessment to estimate their intellectual disability level based on criteria from the Diagnostic and Statistical Manual of Mental Disorders, 4th Edition-Text Revision (American Psychiatric Association, 1994). A trained evaluator then individually assessed the participants in a 90min session aimed at exploring a wide range of cognitive and functional domains. The cognitive tests were presented in a fixed order to allow adequate intervals for delay trials on measures of episodic memory (see Supplementary Table B.1.). All tasks were carried out in a quiet, comfortable room. While participants completed the neuropsychological testing, parents, caregivers or legal guardians answered questionnaires measuring functionality in the participants' daily lives using questionnaires for the following domains: adaptive behavior, quality of life (QoL), quality of sleep, and neuropsychiatric symptoms. Measures of adaptive behavior were obtained with the adult version of the Adaptive Behavior Assessment System-Second Edition (ABASII). Quality of life was assessed with the parents'/guardians' version of the Kidscreen-27. Quality of sleep was explored with The Pittsburgh Sleep Quality Index (PSQI), and neuropsychiatric symptoms were assessed with the Neuropsychiatric Inventory (NPI). IQ was estimated using The Kaufman Brief Intelligence Test (K-BIT). A more detailed description of the complete neuropsychological battery and references can be found in the Supplemental Materials (A.1 and A.2). None of the participants required the presence of their parents or legal guardians to perform cognitive testing.

\section{Neuropsychological Testing}

The following cognitive domains were explored: psychomotor speed, attention, episodic memory, executive functions, and language. Several tests from the Cambridge Neuropsychological Test Automated Battery (CANTAB) (Robbins and Sahakian, 1996) were employed in addition to standard paper and pencil tests. Psychomotor speed was measured with the Motor Screening Test (MOT, CANTAB). Attention was assessed by means of simple reaction time and span capacity measures using the Simple Reaction Time task (SRT, CANTAB), the Spatial Span forward recall (SSP, CANTAB) and the Digit Span forward recall from the Wechsler Adult Intelligence Scale-III (WAISIII) that evaluated visual and verbal information, respectively.
Measures of visual episodic memory and learning were obtained using the CANTAB Paired Associates Learning (PAL) and the Pattern Recognition Memory Test (PRM, CANTAB), and verbal episodic memory using the Cued Recall Test (CRT). Regarding executive functioning, fractioned components of verbal fluency, working memory, planning, mental flexibility, and inhibitory control were explored. Verbal word fluency was measured by means of the semantic fluency word generation task (animals in $1 \mathrm{~min}$ ). Working memory for visual and verbal information was assessed with the Spatial Span backward recall (SSP, CANTAB) and the Digit Span backward recall (WAIS-III), respectively. Planning capacity was measured using the Tower of London from Drexel University (ToLDx) and mental flexibility with the Weigl Color-Form Sort Test. The Cats and Dogs Test was used to assess response inhibition. Finally, measures of expressive and receptive language were obtained by means of the Boston Naming Test and the Token Test, respectively. Only adult versions of the selected cognitive tests were employed with the exception of three specific tests for adults with intellectual disability due to the complexity of the tasks. These included the assessment of verbal episodic memory (Cued Recall Test), executive components of inhibition (Cats and Dogs) and mental flexibility (Weigl Sorting Test). We also administered the child's version of the ToLDx for the planning task to avoid floor effects. The cognitive tests were presented in a fixed order to allow adequate intervals for delay trials on measures of episodic memory. In addition, parallel versions of episodic memory tests were used to control for learning effects. Regarding the tests selected from the CANTAB, only clinical versions were administered.

To perform the comparison of our sample of DS participants with typically developed participants, test scores from normative data provided by the test publishers and normative studies for subjects of the same age range of our study (16-39 years) were employed. (1) For the analyses of CANTAB tests, we used norms derived from 51 to 199 control subjects reported in the CANTAB standard norm database (see Robbins et al., 1997, 1998, for a description of part of these data ${ }^{1}$. The Cambridge Cognition website http://www.cambridgecognition. com/technology provides a practical demonstration of the tests used). (2) For the analyses of paper and pencil tests, we used normative data from 84 to 87 participants (18-34 years old) from the Spanish Multicenter Normative Studies NEURONORMA young adults Project; (Peña-Casanova et al., 2012). (3) For the analyses of ToLDx results, as a child's version had been used, normative data from 76 participants (13-15 years) was selected (Culbertson and Zillmer, 2005), so that it better matched our sample. Similar analyses could not be carried out for performance on verbal episodic memory, mental flexibility, and response

\footnotetext{
${ }^{1}$ Tables for the Cantab test battery are provided in electronic format alongside the product as standard. This allows the replicability of the present data reported in this paper. Due to the fact that norms are copyrighted material, these can't be reproduced in the present study. In the specific case of the Cantab tests, the papers cited report only part of the normative sample included in the current norms, therefore do not correspond precisely to the figures. The present figures correspond to the current Cantab norms, as available with the test.
} 
inhibition, due to the lack of normative data from typically developed adults for these tests.

This battery was developed, and is currently being used, in a longitudinal, randomized, double blind, placebo-controlled Phase II trial conducted by our research team in young adults with Down syndrome (the TESDAD study; De la Torre et al., 2014). In the present work, only baseline neurocognitive results from the TESDAD study are reported.

\section{Statistical Analysis}

The first step consisted of a descriptive analysis of the sociodemographic and clinical parameters of all the participants at baseline. Descriptive analyses were also carried out for all neuropsychological variables, providing measures of mean, standard deviation, and maximum and minimum values in the case of quantitative variables. In order to detect the presence of significant ceiling or floor effects in the variables, frequencies and percent were computed. Variables in which more than $10 \%$ of the sample obtained the maximum or the minimum score, and/or exhibited a significant absolute skewness index $(>2)$ were categorized as having ceiling or floor effects.

We compared the DS group test scores of each cognitive variable to previously published normative data from agematched healthy controls. Test scores of our DS participants could not be compared to normative data for those tests specifically developed for the assessment of participants with intellectual disability (CRT, Weigl, Cats and Dogs). In order to quantify and determine the gap between DS and normative groups, Cohen's effect size ("Cohen's $d$ "), which is the difference of the means of two independent samples divided by the pooled standard deviation, together with its $95 \%$ confidence interval was calculated for all cognitive variables (Choen, 1988). Effect size differences higher than one and a half pooled standard deviations $(|d|>1.5)$ in cognitive performance between DS participants and age-matched normally developed adults were considered key cognitive processes substantially impaired in DS. In order to assess the severity of impairment the following categories were established: severe impairment (effect size differences larger than three pooled standard deviations: $|d|>3$ ); substantial impairment $(|d|>1.5)$; moderate impairment $(|d|>1)$; and mild impairment $(|d|>0.5)$.

To study possible differences in cognitive and functional performance according to IQ, gender, and age, ANCOVA models were fitted for all neurocognitive measures including these three variables of interest. For the analyses, the IQ was categorized into two groups: mild/moderate (IQ $\geq 40$ ) and severe (IQ $<40$ ) within the range of mental disability level. Concerning the two categorical variables, these models provide an adjusted estimation of the mean differences between persons with DS with IQ $<40$ and persons with DS with IQ $\geq 40$, on one hand, and female and male persons with DS, on the other hand. In case of variable age, the models provide an adjusted estimation of the mean difference associated to 1 year of age difference in persons with DS. The differences were considered to be statistically significant if the resulting $p$-value was less than 0.05 . Finally, to explore the relationships between cognitive performance and functional outcome, the Pearson correlation coefficient was calculated to determine associations between cognitive variables, IQ (K-BIT standardized score) and functional outcomes of adaptive behavior and quality of life. We only report moderate and strong correlations $(r \geq 0.4)$. All statistical analyses were performed with the statistical software package $\mathrm{R}$ (The $\mathrm{R}$ Foundation for Statistical Computing), v3.0.2.

\section{Results}

\section{Descriptive Demographic and Clinical Data of the Participants}

Socio-demographic data and clinical parameters of the 86 DS participants are provided in Table 1. 51.2\% were male and the mean age was 23.3 years [standard deviation $(S D)=4.3$ years; range 16-34 years]. The median IQ for the full sample was 41 [K-BIT standardized score: 105 ( $S D=17.8$; range $80-180$; IQ score $(S D)=8.3$; range $40-86)$ ], concentrating a slightly higher proportion of participants with moderate intellectual disability (IQ $\geq 40: 58.1 \% ; n=50$ ) in comparison to those within the severe mental disability range (IQ < 40: $41.9 \% ; n=36$ ). In terms of gender, the median IQ for males was 40 [K-BIT standardized score: $102(S D=19$; range $80-180)$ ] and 42 for females [K-BIT standardized score: $108(S D=16$; range $80-154)]$. The average

TABLE 1 | Sociodemographic characteristics and clinical parameters at baseline.

$(n=86)$

\begin{tabular}{ll} 
AGE & $23.3(4.3)$ \\
GENDER & \\
Female & $42(48.8 \%)$ \\
Male & $44(51.2 \%)$ \\
EDUCATION (YEARS) & $13(1.9)$ \\
HANDEDNESS & \\
Right & $67(79.8 \%)$ \\
Left & $17(20.2 \%)$ \\
INTELLECTUAL DISABILITY LEVEL & \\
Mild/moderate (IQ $\geq 40)$ & $50(58.1 \%)$ \\
Severe (IQ < 40) & $36(41.9 \%)$ \\
INTELLECTUAL QUOTIENT (IQ) & \\
IQ & $41^{\mathrm{b}}$ \\
K-BIT standardized score & $105(17.8)$ \\
Male (standardized; IQ) & $102(19) ; 40^{\mathrm{b}}$ \\
Female (standardized; IQ) & $108(16) ; 42^{\mathrm{b}}$ \\
DS GENETIC VARIATIONS & \\
Trisomy 21 & $82(95.3 \%)$ \\
Mosaic & $1(1.1 \%)$ \\
Translocation & $2(2.3 \%)$ \\
\hline Partial & $1(1.1 \%)$ \\
\hline
\end{tabular}

Results are presented as mean (standard deviation) for continuous variables and absolute frequency (relative frequency) for categorical variables.

${ }^{a}$ Average years of school attendance in specialized or non-specialized educational centers.

${ }^{b}$ Only the median is reported because values below 40 cannot be determined exactly. 
years of schooling (regular school attendance in specialized or non-specialized educational centers) was 13 ( $S D=1.9$; range 10-18). In terms of DS genetic variations, the sample showed the usual proportion for this population: most participants had full trisomy 21 (simple: 95.3\%, $n=82$ ), two participants translocation $(2.3 \%)$, one partial trisomy $(1.1 \%)$, and one mosaic (1.1\%).

From the eighty-six participants that participated in the study, 75 were able to reliably complete all cognitive procedures at baseline. Eleven participants could not perform the entire cognitive assessment protocol due to cognitive or behavioral alterations that interfered with testing. From those, 7 participants presented marked language deficit (significant speech and/or comprehension limitations), and 3 participants presented behavioral disturbances or mental block. One case showed poor collaboration during the assessment. Only data from these 11 participants for those tests successfully completed were included in the analyses.

Ceiling effects were found for a few variables in the following tests: the Cued Recall test (CRT), the Paired Associates Learning (PAL), the Cats and Dogs and the Simple Reaction Time (SRT). These were observed in the CRT for the total immediate recall (A1-A3 total recall) and the total delayed recall, in the PAL for the number of stages completed, in the Cats and Dogs for the correct score, and in the SRT for the percent of correct answers. Regarding floor effects, only a few were detected in the verbal and visual span backwards (Digit and SSP Visual Span) and in the total score of the Weigl Sort Test.

\section{Cognitive Performance in DS Participants Compared to Standard Norms}

Descriptive analyses, Cohen effect sizes $(d)$, and confidence intervals (95\% CI) of cognitive performance in DS and agematched typically developed adults are summarized in Table 2. Cohen effect sizes on the differences of cognitive performance between DS young adults and euploid subjects revealed the following continuum in the magnitude $(d)$ of the deficits in DS: a severe dysfunction of language capacity, a substantial deficit on attention span and executive functions, a moderate deficit in episodic memory and learning abilities, and mild differences in psychomotor speed (Figure 1).

\section{Impact of Intellectual Quotient (IQ), Gender, and Age on Cognitive Performance and Functional Outcomes}

ANCOVA models were applied to analyze effects of IQ, gender, and age on the baseline cognitive performance of DS participants, adjusting for co-variables (Tables 3-5). IQ was related to the significant $(p<0.05)$ differences in measures of cognitive capacity between participants of IQ $<40$ and those of IQ $\geq$ 40 , with the exception of performance on the SRT, Digit Span Backwards and the Weigl Sort Test. These assessing reaction time, verbal working memory and mental flexibility, respectively. As expected, in all cases higher IQ levels were associated with greater cognitive attainment irrespective of chronological age or gender (i.e., comparing subjects of equal age and gender). In addition, significant effects of IQ level were observed in adaptive behavior in most functional skill areas assessed with the ABAS-II such as Communication, Community Use, Functional Academics, Home Living, Health and Safety, Self-Direction, Social Skills, and ABAS total score $(p<0.05)$. Once again, those participants with higher IQ showed better outcomes in adaptive behavior and thus better competence in daily living. However, no significant effect of IQ emerged on the Kidscreen-27 ( $p>0.05)$ which assessed different aspects of quality of life.

Concerning gender, significant differences between men and women were mainly observed in cognitive performance and less in functional outcomes. Women performed significantly better than men of the same age and IQ in most cognitive tests (Tables 3-5), with the most consistent differences occurring in episodic memory and executive functioning (Figure 2). Women also responded better in episodic memory tests, in particular visual associative memory (PAL) and free recall of verbal information (CRT) $(p<0.05)$, but not in visual memory recognition (PRM; $p>0.05$ ). Concerning executive functions, women showed significantly better performance $(p<0.05)$ in cognitive flexibility and planning. Furthermore, they exhibited higher scores in receptive language and attention measures of span capacity, and better accuracy in the simple reaction time task $(p<0.05)$. Gender-related differences were also observed in the functional domain, with women having a significantly better performance than men in adaptive behavior, specifically in Functional Academic (emergent literacy and numeracy basics for current life use) $(p<0.05)$, but described lower health perception regarding their physical wellbeing as reported by parents on the Kidscreen-27 (Kidscreen 27-Physical; $p=0.04$ ). Overall, these results indicate that gender exerts significant effects on cognitive and functional capacities in DS participants, favoring women against men in cognitive functioning and adaptive skills but not in QoL.

Significant negative trends rarely emerged on quality of life outcomes linked to the effect of age in DS participants after adjusting for IQ and gender. Age did not affect adaptive behaviors, nor most measures of quality of life significantly. However, age did affect psychological well-being, which affected total quality of life $(p<0.03)$. Parents responding to the Kidscreen 27 Psychological and Total score items indicated poorer psychological wellbeing and overall health perception as the children grew older.

\section{Relationship between Cognitive Deficits and Functional Outcome}

The Pearson correlation coefficient was calculated to assess the relationships between cognition and functionality, in order to identify meaningful cognitive measures of potential change for clinical trials. Moderate associations emerged among a wide spectrum of cognitive measures and IQ with specific adaptive skills, or the total score in the ABAS-II, while no association was detected with quality of life measures.

The strongest associations were found between cognitive performance and functional academic skills (ABAS-II). Positive associations emerged between Functional Academics and measures of receptive and expressive language (Token Test: $r=0.65,[0.51,0.76]$; Boston Naming: $r=0.42,[0.22,0.58])$ and 
TABLE 2 | Cognitive performance in Down syndrome participants compared to standard norms.

\begin{tabular}{|c|c|c|c|c|c|c|c|c|c|c|}
\hline \multirow[t]{2}{*}{ Groups } & \multicolumn{4}{|c|}{ Down syndrome } & \multicolumn{4}{|c|}{ Reference standard norms } & \multirow[t]{2}{*}{ Cohen's- $d^{b}$} & \multirow[t]{2}{*}{$95 \% \mathrm{Cl}^{\mathrm{C}}$} \\
\hline & Mean (SD) ${ }^{a}$ & $\begin{array}{c}\text { Range } \\
\text { (min-max) }\end{array}$ & $\begin{array}{c}\text { Age } \\
\text { range }\end{array}$ & $n$ & Mean (SD) & $\begin{array}{c}\text { Range } \\
\text { (min-max) }\end{array}$ & $\begin{array}{c}\text { Age } \\
\text { range }\end{array}$ & $n$ & & \\
\hline \multicolumn{11}{|l|}{ ATTENTION } \\
\hline SRT: simple RT latency $\left(\mathrm{ms}^{\mathrm{d}}\right)$ & $588.0(220.0)$ & $302-1430$ & $16-34$ & 85 & - & - & - & - & - & - \\
\hline SRT: simple RT(\%) correct & $96.6(5.7)$ & $68-100$ & $16-34$ & 85 & - & - & - & - & - & - \\
\hline SSP visual span & $3.2(1.5)$ & $0-6$ & $16-34$ & 86 & 6.7 (1.3) & $3-9$ & $16-39$ & 199 & -2.5 & $-2.8,-2.2$ \\
\hline Digit span & $2.8(0.8)$ & $0-4$ & $16-34$ & 86 & $6.2(1.0)$ & $4-9$ & $18-34$ & 84 & -3.6 & $-4.1,-3.1$ \\
\hline \multicolumn{11}{|l|}{ PSYCHOMOTOR SPEED } \\
\hline MOT: mean latency (ms) & $1138.0(391.0)$ & 576-2645 & $16-34$ & 86 & $928.0(254.0)$ & 445-2204 & $16-39$ & 143 & 0.7 & $0.4,0.9$ \\
\hline \multicolumn{11}{|l|}{ VISUAL EPISODIC MEMORY } \\
\hline \multicolumn{11}{|l|}{ Visual associative memory } \\
\hline PAL: stages completed & $6.7(1.8)$ & $1-8$ & $16-34$ & 85 & $8.0(0.04)$ & $7-8$ & $16-39$ & 175 & -1.2 & $-1.5,-0.2$ \\
\hline PAL: first trial memory & $11.0(4.8)$ & $0-21$ & $16-34$ & 85 & $21.6(3.5)$ & $7-26$ & $16-39$ & 146 & -2.6 & $-3.0,-2.3$ \\
\hline PAL: total errors adjusted & $70.1(60.90)$ & $6-213$ & $16-34$ & 85 & $7.2(9.1)$ & $0-82$ & $16-39$ & 168 & 1.7 & $1.4,2.0$ \\
\hline \multicolumn{11}{|l|}{ Visual recognition } \\
\hline PRM: (\%) immediate recall & $66.9(19.3)$ & $25-100$ & $16-34$ & 86 & $87.8(12.5)$ & $58.30-100$ & $16-39$ & 51 & -1.2 & $-1.6,-0.8$ \\
\hline PRM: (\%) delayed recall & $61.0(18.6)$ & $25-100$ & $16-34$ & 85 & - & - & - & - & - & - \\
\hline \multicolumn{11}{|l|}{ EXECUTIVE FUNCTIONS } \\
\hline \multicolumn{11}{|l|}{ Verbal fluency } \\
\hline Semantic word fluency & $9.4(4.3)$ & $0-21$ & $16-34$ & 85 & $23.6(4.9)$ & $9-34$ & $18-34$ & 87 & -3.1 & $-3.5,-2.6$ \\
\hline \multicolumn{11}{|l|}{ WORKING MEMORY } \\
\hline SSP visual span backwards ${ }^{e}$ & $2.4(1.6)$ & $0-8$ & $16-34$ & 85 & $5.0(0.9)$ & $3-7$ & $18-34$ & 87 & -1.9 & $-2.3,-1.6$ \\
\hline Digit span backwards & $1.4(1.2)$ & $0-3$ & $16-34$ & 86 & $5.2(1.3)$ & $3-8$ & $18-34$ & 84 & -3.0 & $-3.4,-2.6$ \\
\hline \multicolumn{11}{|l|}{ Planning ${ }^{f}$} \\
\hline ToLDx: total correct Score & $1.7(1.4)$ & $0-5$ & $16-34$ & 82 & $4.4(1.7)$ & - & $13-15$ & 76 & -1.8 & $-2.1,-1.4$ \\
\hline ToLDx: total move score & $84.7(39.2)$ & $0-170$ & $16-34$ & 82 & $29.0(13.5)$ & - & $13-15$ & 76 & 1.9 & $1.5,2.2$ \\
\hline ToLDx: probl-solving time $\left(\mathrm{s}^{9}\right)$ & $763.0(289.0)$ & $0-1200$ & $16-34$ & 82 & $214.7(98.3)$ & - & $13-15$ & 76 & 2.5 & $2.1,2.9$ \\
\hline \multicolumn{11}{|l|}{ LANGUAGE } \\
\hline \multicolumn{11}{|l|}{ Comprehension } \\
\hline Token Test: total score & $19.6(6.5)$ & $1-35$ & $16-34$ & 85 & $35.5(0.7)$ & $33-36$ & $18-34$ & 87 & -3.4 & $-3.9,-3.0$ \\
\hline \multicolumn{11}{|l|}{ Naming } \\
\hline Boston Naming Test: total score & $24.0(9.5)$ & $0-53$ & $16-34$ & 82 & $52.4(4.3)$ & $39-59$ & $18-34$ & 87 & -3.9 & $-4.4,-3.4$ \\
\hline $\begin{array}{l}\text { a Results are presented as mean (st } \\
\text { b Cohen's effect size. Differences la } \\
\text { o.5). } \\
{ }^{c} \text { Confidence Interval. } \\
{ }^{d} \text { Milliseconds. } \\
{ }^{e} \text { Results are compared to standard } \\
{ }^{f} \text { Results are compared to standard } \\
g \text { Seconds. }\end{array}$ & $\begin{array}{l}\text { Is from the Cors } \\
\text { s from adolesce }\end{array}$ & $\begin{array}{l}\text { ck provideo } \\
\text { pically deve }\end{array}$ & $\begin{array}{l}\text { he NE } \\
\text { d sub }\end{array}$ & & $\begin{array}{l}\text { A young adults } \\
3-15 \text { vears. }\end{array}$ & $\|>1.5) ; m$ & imp & 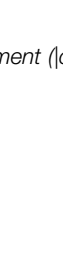 & 1); and mild & $\operatorname{rment}(|d|>$ \\
\hline
\end{tabular}

executive components of verbal fluency (Semantic word fluency: $r=0.40,[0.20,0.56])$. Positive associations were also found for working memory for visual and verbal information (SSP span backwards: $r=0.47,[0.29,0.62]$; Digit span backwards: $r=0.48,[0.30,0.63]$ ), planning (ToLDx Total correct score: $r=0.53,[0.35,0.67])$, attention span for visual and verbal information (SSP span: $r=0.56$, [95\%-CI: 0.39, 0.69]; Digit span: $r=0.46,[0.28,0.62])$, and memory recognition for immediate and delayed recall of visual information (PRM (\%) immediate recall: $r=0.45,[0.26,0.60]$; PRM (\%) delayed recall: $r=0.48,[0.29,0.63])$. Negative associations were found between Functional Academics and error rate in the visual associative learning task (PAL total errors adjusted: $r=-0.56$, $[-0.69,-0.39])$ and planning accuracy deficits (ToLDx Total move score: $r=-0.51,[-0.66,-0.33])$. These results indicate that higher attainment in functional academic skills (emergent literacy and numeracy basics for current life use) could be strongly linked to a more efficient overall cognitive functioning in DS participants. In addition, a positive consistent association emerged between Functional Academics and IQ (IQ: $r=0.52$, $[0.35,0.66])$. These results confirm previous assumptions, and suggest that specific cognitive measures are potentially good end-point measures for estimating changes in functional outcome in clinical trials. 


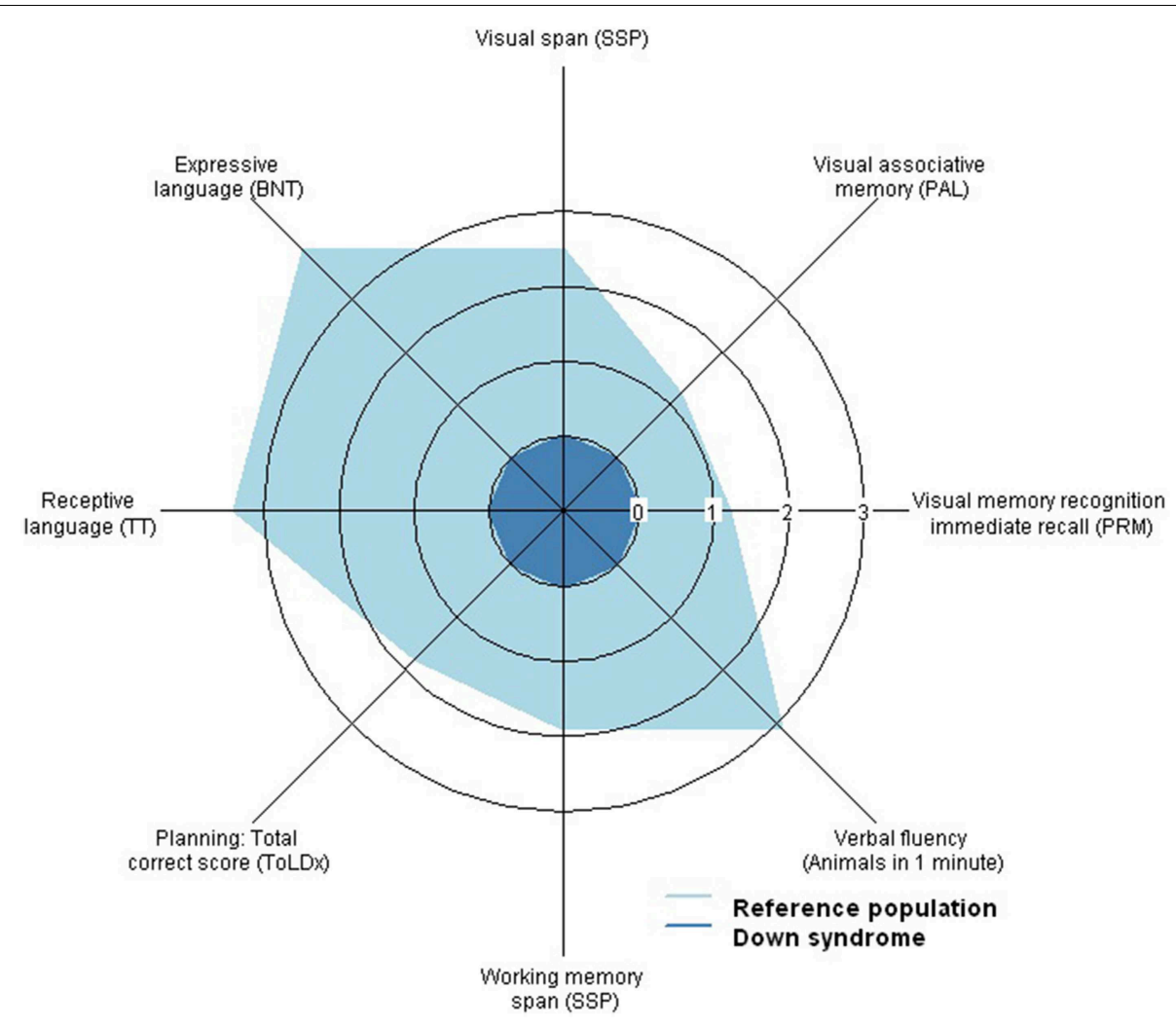

FIGURE 1 | Radar plot representing the severity of cognitive impairment in Down syndrome (DS) compared to age-matched typically developed adults on attention, memory, language and executive functioning components. Axis values indicate the absolute value of Cohen's effect size $(d)$ for the differences between both populations.
For this purpose, the performance of the participants with DS has been standarized to 1 which is equivalent to an effect size of $d=0$. DS adults show a severe dyfunction of language capacity $(|d|>3)$, a substantial deficit on attention span and executive functions $(|d|>1.5)$ and a moderate deficit in episodic memory $(|d|>1)$.
Communication and Community use subscales of the ABASII also correlated consistently with cognitive attainment. Positive correlations were found between communicative abilities and visual attention span (SSP span: $r=0.40,[0.20,0.56]$ ), receptive and expressive language (Token Test: $r=0.52$, [0.34, 0.66]; Boston Naming Test: $r=0.41,[0.21,0.58])$. In addition, a negative association was observed between ability to communicate and the number of errors performed during visual associative learning (PAL total errors adjusted: $r=$ $-0.46,[-0.61,-0.27])$. Community use was mainly related to cognitive measures of receptive language (Token Test: $r=0.52$, $[0.30,0.63])$ and executive components of working memory for visual and verbal information (SSP span backwards: $r=0.43$, [0.24, 0.59]; Digit span backwards: $r=0.41,[0.21,0.57])$ and planning (ToLDx Total correct score: $r=0.40,[0.19,0.56]$ ). In all cases, a higher performance in specific cognitive tests was consistently related to a greater ability to communicate in daily life and higher independent functioning within the community.

Finally, language comprehension emerged as having the most consistent association with the overall score in adaptive behavior (ABAS Total Score) (Token Test: $r=0.52$, [0.35, 0.66]). Other cognitive measures were consistently correlated with the ABAS Total Score such as visual attention span (SSP span: $r=0.40,[0.20,0.56])$ and executive components of visual working memory (SSP span backwards: $r=0.41,[0.22,0.57]$ ) and planning (ToLDx Total correct score: $r=0.41,[0.21$, 0.58]; ToLDx Total move score: $r=-0.48$, [-0.63, -0.29]). These results indicate that better language comprehension, attention, and executive functioning are the cognitive capacities more closely related to higher competence in overall adaptive skills and, therefore, in everyday life independence for DS participants.

\section{Discussion}

This study proposes a new neurocognitive battery for clinical trials in DS adults (the TESDAD battery), using chronologically age-matched fully-developed subjects for comparison as a more useful approach for the characterization of the DS cognitive profile. This battery also provides clinically useful measures closely linked to prefrontal-temporal brain networks and to functional competence in everyday life following interventional studies. Finally, our study emphasizes the need to determine the modulation effects of intellectual quotient, gender, and age on cognitive treatments. 
TABLE 3 | Impact of intellectual quotient, gender, and age on attention, psychomotor, memory, and language performance in Down syndrome participants.

\begin{tabular}{|c|c|c|c|c|c|c|c|c|c|}
\hline \multirow[t]{2}{*}{ Down syndrome } & \multicolumn{3}{|c|}{ Intelligence quotient ( $<40$ vs. $\geq 40$ ) } & \multicolumn{3}{|c|}{ Gender (female vs. male) } & \multicolumn{3}{|c|}{ Age } \\
\hline & Estimate ${ }^{a}$ & $95 \% \mathrm{Cl}^{\mathrm{b}}$ & $p$-values & Estimate $^{c}$ & $95 \% \mathrm{Cl}$ & $p$-values & Estimate $^{\mathrm{d}}$ & $95 \% \mathrm{Cl}$ & $p$-values \\
\hline \multicolumn{10}{|l|}{ ATTENTION } \\
\hline SRT: simple RT latency $\left(\mathrm{ms}^{\mathrm{e}}\right)$ & 57.2 & {$[-39.1 ; 153.6]$} & 0.24 & -37.7 & {$[-134.2 ; 58.8]$} & 0.44 & 8.68 & {$[39.1 ; 153.6]$} & 0.13 \\
\hline SRT: simple RT(\%) correct & -1.9 & {$[-4.3 ; 0.5]$} & 0.12 & 2.8 & {$[0.3 ; 5.2]$} & $0.02^{*}$ & -0.25 & {$[-0.5 ; 0.03]$} & 0.08 \\
\hline SSP visual span & -0.8 & {$[-1.4 ;-0.2]$} & $0.01^{*}$ & 0.7 & {$[0.1 ; 1.3]$} & $0.02^{*}$ & -0.03 & {$[-0.0 ; 0.03]$} & 0.34 \\
\hline Digit span & -0.4 & {$[-0.7 ;-0.03]$} & $0.03^{\star}$ & 0.3 & {$[0.01 ; 0.7]$} & $0.04^{*}$ & 0.02 & {$[-0.01 ; 0.06]$} & 0.20 \\
\hline \multicolumn{10}{|l|}{ PSYCHOMOTOR SPEED } \\
\hline MOT: mean latency (ms) & 176.1 & {$[9.3 ; 342.9]$} & $0.03^{*}$ & 3.6 & {$[-164.2 ; 171.4]$} & 0.96 & 15.7 & {$[-4.2 ; 35.5]$} & 0.12 \\
\hline \multicolumn{10}{|l|}{ EPISODIC MEMORY } \\
\hline \multicolumn{10}{|l|}{ Visual associative memory } \\
\hline PAL: stages completed & -1.0 & {$[-1.8 ;-0.3]$} & $0.006^{\star \star}$ & 1.30 & {$[0.6 ; 2.0]$} & $0.001^{\star \star}$ & 0.02 & {$[-0.06 ; 0.10]$} & 0.61 \\
\hline PAL: first trial memory & -1.8 & {$[-3.7 ; 0.2]$} & $0.07^{+}$ & 3.47 & {$[1.5 ; 5.4]$} & $0.001^{\star \star}$ & 0.002 & {$[-0.2 ; 0.2]$} & 0.98 \\
\hline PAL: total errors adjusted & 35.1 & {$[11.8 ; 58.4]$} & $0.004^{\star \star}$ & -52.24 & {$[-75.6 ;-28.9]$} & $<0.001^{\star * \star}$ & 0.1 & {$[-2.7 ; 2.9]$} & 0.94 \\
\hline \multicolumn{10}{|l|}{ Visual recognition } \\
\hline PRM: (\%) immediate recall & -12.1 & {$[-20.2 ;-4.1]$} & $0.004^{\star \star}$ & 4.25 & {$[-3.8 ; 12.3]$} & 0.29 & -0.6 & {$[-1.6 ; 0.3]$} & 0.20 \\
\hline PRM: (\%) delayed recall & -8.0 & {$[-16.0 ; 0.01]$} & $0.05^{+}$ & 2.04 & {$[-6.0 ; 10.1]$} & 0.61 & -0.7 & {$[-1.6 ; 0.3]$} & 0.15 \\
\hline \multicolumn{10}{|l|}{ Verbal episodic memory } \\
\hline CRT:A1-A3 free immediate recall & -2.5 & {$[-5.0 ; 0.1]$} & $0.05^{+}$ & 3.6 & {$[1.0 ; 6.1]$} & $0.007^{\star \star}$ & 0.1 & {$[-0.2 ; 0.4]$} & 0.68 \\
\hline CRT:A1-A3 total immediate recall & -0.7 & {$[-1.5 ; 0.2]$} & 0.11 & 0.8 & {$[-0.01 ; 1.7]$} & $0.05^{+}$ & 0.03 & {$[-0.1 ; 0.1]$} & 0.48 \\
\hline CRT: free delayed recall & -0.9 & {$[-2.0 ; 0.2]$} & 0.11 & 1.5 & {$[0.4 ; 2.6]$} & $0.008^{* \star}$ & 0.1 & {$[-0.1 ; 0.2]$} & 0.33 \\
\hline CRT: total delayed recall & -0.1 & {$[0.4 ; 0.2]$} & 0.45 & 0.05 & {$[-0.2 ; 0.3]$} & 0.68 & 0.02 & {$[-0.01 ; 0.05]$} & 0.24 \\
\hline \multicolumn{10}{|l|}{ LANGUAGE } \\
\hline \multicolumn{10}{|l|}{ Comprehension } \\
\hline Token Test: total score & -5.6 & {$[-8.1 ;-3.0]$} & $<0.001^{\star * \star}$ & 3.25 & {$[0.7 ; 5.8]$} & $0.01^{*}$ & 0.01 & {$[-0.3 ; 0.3]$} & 0.97 \\
\hline \multicolumn{10}{|l|}{ Naming } \\
\hline Boston Naming Test: total score & -9.9 & {$[-13.6 ;-6.1]$} & $<0.001^{\star \star \star}$ & 2.22 & {$[-1.5 ; 5.9]$} & 0.2 & -0.1 & {$[-0.6 ; 0.3]$} & 0.59 \\
\hline $\begin{array}{l}\text { a Estimated mean difference between } \\
{ }^{b} \text { Confidence Interval. } \\
{ }^{c} \text { Estimated mean differences betwee } \\
{ }^{d} \text { Estimated mean differences associa } \\
{ }^{e} \text { Milliseconds. } \\
{ }^{*} \text { Significant estimated effects of the } v \\
{ }^{* *} \text { Significant estimated effects of the } \\
{ }^{* * \star} \text { Significant estimated effects of the } \\
+ \text { Marginal non-significant estimated }\end{array}$ & $\begin{array}{l}\text { persons with } \\
\text { ted female and } n \\
\text { ariable of intere } \\
\text { variable of inter } \\
\text { variable of inte } \\
\text { effects of the }\end{array}$ & $\begin{array}{l}\text { S with } I Q<40 \text { an } \\
\text { ale persons with } D \\
\text { of age difference } \\
\text { st }(p<0.05) \text {. } \\
\text { est }(p<0.01) \text {. } \\
\text { rest }(p<0.001) \text {. } \\
\text { riable of interest. }\end{array}$ & $\begin{array}{l}\text { persons with } \\
\text { persons with } \\
\text { persor for }\end{array}$ & $\begin{array}{l}\text { S with } I Q \geq 40 \\
\text { and age. } \\
\text { S adjusted for }\end{array}$ & Q and gender. & and age. & & & \\
\hline
\end{tabular}

\section{Magnitude of Cognitive Deficits in DS Adults}

The results of this study support the demonstration (Abbeduto et al., 2001; Laws and Bishop, 2004; Næess et al., 2011) that language impairment is the strongest cognitive disturbance in young DS adults with receptive abilities being more preserved than expressive skills. In addition, and as previously reported, the relative strength of visuospatial processing over verbal tasks suggests that language impairment is the primary landmark of global intellectual impairment in DS (Lanfranchi et al., 2004; Edgin et al., 2010b). After language, attention and executive functions differed more from standard norms, with verbal span capacity and verbal fluency presenting the strongest deficiencies, followed by working memory; in contrast, planning was relatively more preserved. These results concur with the portrayal of a broad, marked dysexecutive syndrome in DS (Rowe et al., 2006; Lanfranchi et al., 2010) probably due to the reduced size of the prefrontal cortex (Contestabile et al., 2010; Lott and Dierssen, 2010), in particular of the anterior cingulate gyrus, medial, and dorsolateral prefrontal cortices as reported in neuroimaging studies of DS adults (Raz et al., 1995; White et al., 2003; Carducci et al., 2013). Areas such as these actively contribute to mnemonic processing and executive control in euploid subjects (Braver, 2001; Wager and Smith, 2003; Blumenfeld et al., 2011), thus generalized impairment of high order frontal-dependent processes, together with language, represent a crucial target for therapeutic intervention in DS.

Overall performance in episodic memory was also poor although superior to language, attention, and executive functions. It is noteworthy that our results showed a better preservation of hippocampal-dependent memory processes, such as storage and consolidation, compared to frontal-mediated processes (information coding, retrieval strategies and attention control) in 
TABLE 4 | Impact of intellectual quotient (IQ), gender, and age on executive functioning in Down syndrome participants.

\begin{tabular}{|c|c|c|c|c|c|c|c|c|c|}
\hline & \multicolumn{9}{|c|}{ Down syndrome } \\
\hline & \multicolumn{3}{|c|}{ Intelligence Quotient ( $<40$ vs. $\geq 40$ ) } & \multicolumn{3}{|c|}{ Gender (female vs. male) } & \multicolumn{3}{|c|}{ Age } \\
\hline & Estimate $^{a}$ & $95 \% \mathrm{Cl}^{\mathrm{b}}$ & $p$-values & Estimate $^{c}$ & $95 \% \mathrm{Cl}$ & $p$-values & Estimate $^{d}$ & $95 \% \mathrm{Cl}$ & $p$-values \\
\hline \multicolumn{10}{|l|}{ EXECUTIVE FUNCTIONS } \\
\hline \multicolumn{10}{|l|}{ Verbal fluency } \\
\hline Semantic word fluency & -2.6 & {$[-4.4 ;-0.8]$} & $0.006^{\star \star}$ & -0.1 & {$[-1.9 ; 1.7]$} & 0.87 & 0.1 & {$[-0.1 ; 0.3]$} & 0.29 \\
\hline \multicolumn{10}{|l|}{ Working memory } \\
\hline SSP visual span backwards & -0.8 & {$[-1.4 ;-0.1]$} & $0.02^{*}$ & 0.7 & {$[0.05 ; 1.4]$} & $0.03^{*}$ & 0.03 & {$[-0.04 ; 0.1]$} & 0.42 \\
\hline Digit span backwards & -0.3 & {$[0.86 ; 0.15]$} & 0.16 & 0.43 & {$[-0.1 ; 0.9]$} & 0.09 & -0.01 & {$[0.04 ; 0.6]$} & 0.64 \\
\hline \multicolumn{10}{|l|}{ Planning } \\
\hline ToLDx: total correct score & -1.0 & {$[-1.6 ;-0.5]$} & $<0.001^{\star \star \star}$ & 0.9 & {$[0.4 ; 1.5]$} & $0.002^{\star \star}$ & -0.03 & {$[-0.1 ; 0.03]$} & 0.36 \\
\hline ToLDx: total move score & 26.3 & {$[10.0 ; 42.7]$} & $0.002^{* \star}$ & -20.9 & {$[-37.2 ;-4.6]$} & $0.01^{*}$ & 0.9 & {$[-1.0 ; 2.8]$} & 0.33 \\
\hline ToLDx: problem-solving time $\left(\mathrm{s}^{\mathrm{e}}\right)$ & 180.3 & {$[58.2 ; 302.4]$} & $0.004^{\star \star}$ & -143.9 & {$[-265.6 ;-22.1]$} & $0.02^{*}$ & 9.2 & {$[-5.1 ; 23.5]$} & 0.20 \\
\hline \multicolumn{10}{|l|}{ Mental flexibility } \\
\hline Weigl sort test: total score & -0.3 & {$[-1.0 ; 0.3]$} & 0.32 & 1.2 & {$[0.5 ; 1.9]$} & $0.001^{\star *}$ & -0.02 & {$[-0.1 ; 0.1]$} & 0.62 \\
\hline \multicolumn{10}{|l|}{ Inhibition } \\
\hline Cats and dogs: total time (s) & 7.6 & {$[0.6 ; 14.7]$} & $0.03^{\star}$ & -2.4 & {$[-9.5 ; 4.6]$} & 0.48 & 0.2 & {$[-0.7 ; 1.0]$} & 0.66 \\
\hline Cats and dogs: correct score & -0.6 & {$[-1.1 ;-0.1]$} & $0.02^{*}$ & -0.01 & {$[-0.5 ; 0.5]$} & 0.96 & -0.02 & {$[0.1 ; 0.03]$} & 0.44 \\
\hline
\end{tabular}

DS. Findings substantiated by the higher performance exhibited in the recognition and cued recall trials as compared to free recall, and by the higher ratio of perseverative errors compared to intrusions in the verbal learning task (see Supplementary Results). This mnemonic profile indicates that poor monitoring and executive control, rather than storage difficulties, are mainly responsible for poor memory performance. In this regard, structural neuroimaging studies have related impaired memory performance in DS adults with reductions in the prefrontal, hippocampus, and parahippocampal areas of these subjects (Krasuski et al., 2002; Teipel et al., 2004; Beacher et al., 2005). Postmortem histological studies have, moreover, consistently demonstrated that the dendritic morphology of hippocampal neurons is compromised in DS adult brains (Ferrer and Gullotta, 1990; Takashima et al., 1994). In summary, our results indicate executive dysfunction as a major factor underlying memory impairment in DS. Thus, effective therapies targeting prefrontaldependent executive functions in this population would enhance cognitive performance.

\section{Effects of IQ, Gender, and Age on Cognitive and Functional Outcomes in DS}

We explored the association of clinical and sociodemographic variables such as IQ, gender, and age with cognitive and functional performance in DS. Our regression analyses, in concurrence with other authors, revealed that the explanation for the extensive variability found in the neurocognitive performance of DS adults lies in the primary variable of the IQ level. The most consistent associations with IQ were found with language, its use in everyday functioning (learning of literacy basics, communication skills, social abilities, and efficient use of community resources), and with global adaptive competence. No effect of IQ was observed, however, on quality of life outcomes. A finding that could partly be explained by the fact that in euploids, emotional aspects are more closely related to QoL perception than IQ (Takeuchi et al., 2014). The use of parent-proxy measures for determining QoL perception in DS is, nevertheless, a surrogate and a probably biased outcome based on QoL self-perception in these subjects.

It is noteworthy that gender showed a widespread influence on cognitive variables whilst its impact on functional outcomes was minor. From our analyses we can conclude that men with DS perform at a significantly poorer level than DS women, in particular with respect to episodic memory and executive processing. They also exhibit poorer functional academic skills in everyday life, but present a higher QoL perception concerning their physical well-being. Although the differences observed in cognitive performance between genders are mild, they may explain the higher IQ level and better competence exhibited by women in everyday functioning, in particular related to command of language. Other studies have also reported that women with trisomy 21 display a higher level of cognitive and adaptive functioning than DS men (Lund, 1988; Määttä et al., 2006). Taken together, these findings suggest that gender 
TABLE 5 | Impact of intellectual quotient (IQ), gender, and age on functional outcomes in Down syndrome participants.

\begin{tabular}{|c|c|c|c|c|c|c|c|c|c|}
\hline & \multicolumn{9}{|c|}{ Down syndrome } \\
\hline & \multicolumn{3}{|c|}{ Intelligence Quotient (<40 vs. $\geq 40$ ) } & \multicolumn{3}{|c|}{ Gender (female vs. male) } & \multicolumn{3}{|c|}{ Age } \\
\hline & Estimate $^{a}$ & $95 \% \mathrm{Cl}^{\mathrm{b}}$ & $p$-values & Estimate $^{c}$ & $95 \% \mathrm{Cl}$ & $p$-values & Estimate $^{\mathrm{d}}$ & $95 \% \mathrm{Cl}$ & $p$-values \\
\hline \multicolumn{10}{|l|}{ ADAPTIVE BEHAVIOR } \\
\hline ABAS-Communication & -8.7 & {$[-13.9 ;-3.6]$} & $0.001^{\star \star}$ & 4.2 & {$[-1.0 ; 9.4]$} & 0.11 & 0.1 & {$[-0.7 ; 0.8]$} & 0.82 \\
\hline ABAS-community use & -9.7 & {$[-15.0 ;-4.4]$} & $<0.001^{\star \star *}$ & 2.8 & {$[-2.5 ; 8.1]$} & 0.29 & 0.5 & {$[-1.1 ; 1.1]$} & 0.13 \\
\hline ABAS-functional academics & -13.3 & {$[-20.4 ;-6.3]$} & $<0.001^{\star \star *}$ & 9.0 & {$[1.9 ; 16.1]$} & $0.01^{*}$ & 0.1 & {$[-0.1 ; 1.0]$} & 0.77 \\
\hline ABAS-home living & -5.6 & {$[-10.6 ;-0.6]$} & $0.02^{*}$ & 4.2 & {$[-0.8 ; 9.3]$} & 0.09 & 0.4 & {$[-0.2 ; 1.0]$} & 0.17 \\
\hline ABAS-health and safety & -5.8 & {$[-9.7 ;-1.8]$} & $0.005^{\star \star}$ & 0.5 & {$[-3.5 ; 4.5]$} & 0.81 & 0.2 & {$[-0.3 ; 0.7]$} & 0.42 \\
\hline ABAS-leisure & -2.5 & {$[-7.6 ; 2.5]$} & 0.32 & 1.2 & {$[-3.8 ; 6.3]$} & 0.62 & -0.2 & {$[-0.8 ; 0.4]$} & 0.50 \\
\hline ABAS-self-care & -1.5 & {$[-5.1 ; 2.2]$} & 0.42 & 2.4 & {$[-1.3 ; 6.0]$} & 0.20 & 0.03 & {$[-0.4 ; 0.5]$} & 0.85 \\
\hline ABAS-self-direction & -8.7 & {$[-14.8 ;-2.5]$} & $0.006^{\star \star}$ & 4.9 & {$[-1.2 ; 11.0]$} & 0.11 & 0.2 & {$[-0.6 ; 0.9]$} & 0.64 \\
\hline ABAS-social skills & -7.6 & {$[-12.4 ;-2.8]$} & $0.002^{\star \star}$ & 1.8 & {$[-2.9 ; 6.6]$} & 0.44 & -0.5 & {$[-1.0 ; 0.1]$} & 0.09 \\
\hline ABAS-work & - & & - & - & & - & - & & - \\
\hline ABAS-total score & -63.4 & {$[-100.4 ;-26.4]$} & $0.001^{\star *}$ & 31.1 & {$[-6.1 ; 68.3]$} & 0.10 & 0.8 & {$[-3.6 ; 5.2]$} & 0.71 \\
\hline \multicolumn{10}{|l|}{ QUALITY OF LIFE } \\
\hline Kidscreen 27-physical & 0.6 & {$[-1.1 ;-2.2]$} & 0.49 & -1.7 & {$[-3.3 ;-0.05]$} & $0.04^{*}$ & -0.2 & {$[-0.4 ; 0.03]$} & 0.09 \\
\hline Kidscreen 27-psychological & 0.5 & {$[-1.2 ;-2.3]$} & 0.53 & 0.2 & {$[-1.5 ; 1.9]$} & 0.82 & -0.2 & {$[-0.4 ;-0.01]$} & $0.03^{*}$ \\
\hline Kidscreen 27-autonomy and parents & 0.1 & {$[-1.1 ; 1.4]$} & 0.80 & 1 & {$[-0.3 ; 2.3]$} & 0.11 & -0.05 & {$[-0.2 ; 0.1]$} & 0.46 \\
\hline Kidscreen 27-peers and social & 0.5 & {$[-1.4 ; 2.4]$} & 0.60 & 0.9 & {$[-1.0 ; 2.8]$} & 0.35 & -0.05 & {$[-0.3 ; 0.2]$} & 0.66 \\
\hline Kidscreen 27-school & - & & - & - & & - & - & & - \\
\hline Kidscreen 27-total score & 2.8 & {$[-3.9 ; 9.6]$} & 0.39 & -1.0 & {$[-7.6 ; 5.6]$} & 0.75 & -0.9 & {$[-1.7 ; 0.1]$} & $0.03^{\star}$ \\
\hline
\end{tabular}

a Estimated mean difference between persons with $D S$ with $I Q<40$ and persons with $D S$ with $I Q \geq 40$ adjusted for gender and age.

b Confidence Interval.

${ }^{c}$ Estimated mean differences between female and male persons with DS adjusted for IQ and age.

${ }^{a}$ Estimated mean differences associated to one year of age difference in persons with DS adjusted for IQ and gender.

* Significant estimated effects of the variable of interest $(p<0.05)$.

** Significant estimated effects of the variable of interest $(p<0.01)$.

${ }^{* * *}$ Significant estimated effects of the variable of interest $(p<0.001)$.

may exert a relevant modulating effect on cognitive functioning in DS participants favoring women, which is not the case in healthy participants. The poorer QoL status in young women with DS compared to men, especially with respect to their physical well-being, may not be characteristic of DS associated with gender, since it has also been reported in woman from euploid population (Torsheim et al., 2006; Michel et al., 2009).

The impact of age on neurocognitive outcomes was negligible and restricted to QoL perception. In a similar manner to healthy adolescents and young adults, increasing age in DS participants was associated with a decline in QoL, in spite of the fact that women reported poorer outcomes compared to men (Bisegger et al., 2005; Michel et al., 2009). Thus, lower QoL with increasing age is not a distinctive trend in DS. No significant impact of age was found on cognitive and adaptive behavior outcomes, probably due to the age range of our sample (16-34 years old), representative of late adolescence and adulthood when the negative consequences of premature aging upon cognition and everyday life competence have not yet been detected. Our results suggest that during this period overall cognitive capacity in DS adults has probably reached a plateau, similar to the scenario of normally developed adults who reach their peak performance between 18 and 30 years of age (Peña-Casanova et al., 2012). Taken together, our results emphasize the need to explore the modulating effects of IQ, gender, and age on cognitive enhancing treatments in the DS population.

\section{Relationship to Functional Outcome in DS Participants for Interventional Studies}

We explored the associations between cognitive performance, IQ, and functional outcomes of adaptive behavior and QoL in DS. The aim was to identify specific relationships between cognitive performance and different aspects of functional outcome that could potentially serve for expecting functional change following interventional studies. Cognitive-related outcomes were closely linked to functional aspects of language and global adaptive competence in everyday life. It is worth mentioning that auditory comprehension and functional academic measures have a great potential as end-point measures of therapeutic intervention for clinical trials: the former as a cognitive key target for therapeutic intervention, and the latter as a primary functional outcome measure of clinical efficacy.

According to the results obtained in the regression analysis, it could be argued that IQ could be a good predictor of functional outcome for longitudinal interventional studies. Specific 


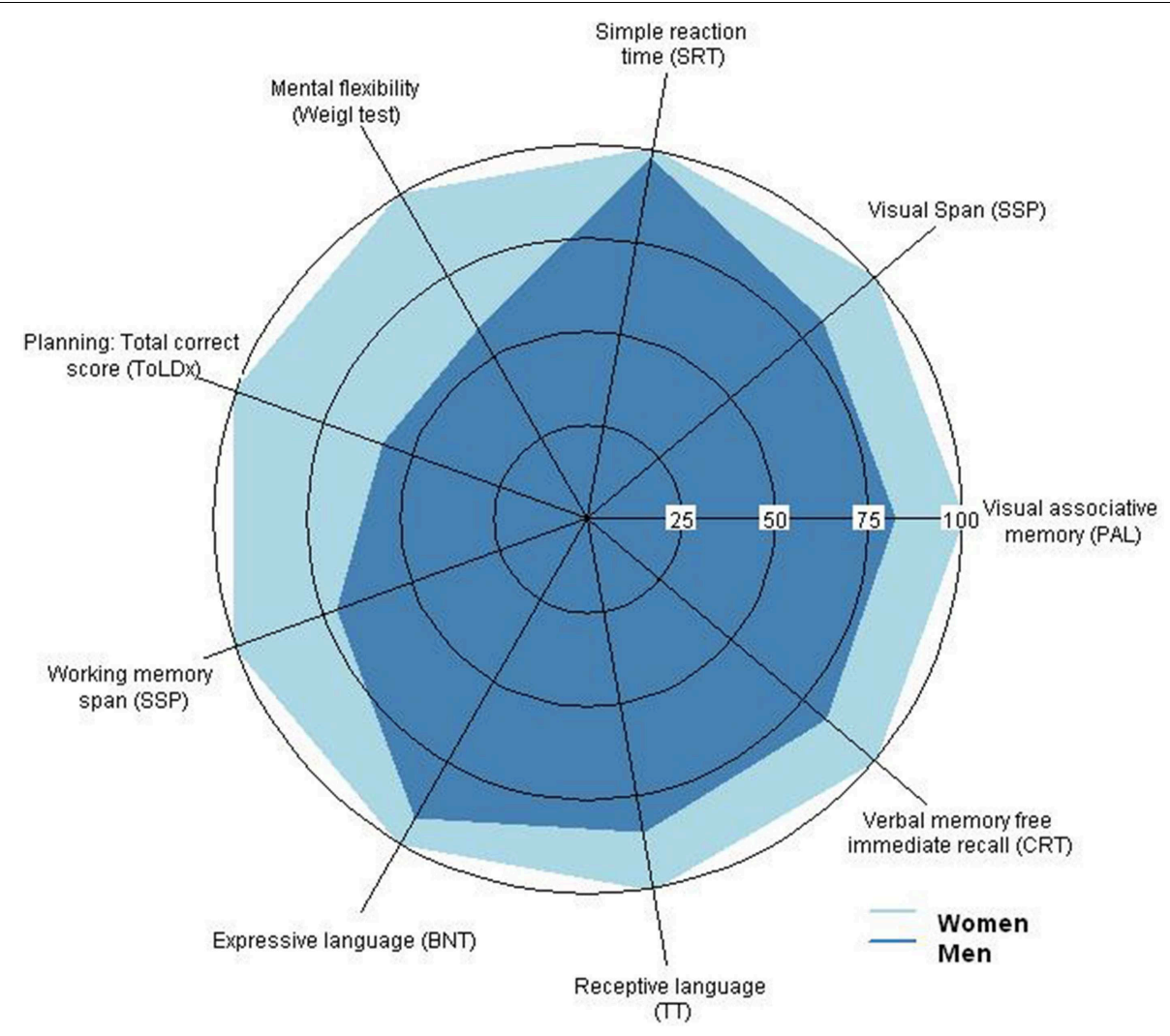

FIGURE 2 | Radar plot representing the statistically significant differences in cognitive performance between men and women with Down Syndrome (DS) on attention, memory, language and executive functioning components. Axis values indicate the performance in percentage relative to the women's performance, which has been set to $100 \%$. Men with DS performed significantly poorer than women in all four cognitive domains. cognitive capacities, however, showed consistent associations with functional outcomes in the univariate analysis. IQ remains stable during adult life whilst cognitive capacities underlying intellectual status, such as attention, memory, language, and executive functions, are dynamic throughout the lifespan. These changes in cognitive capacity provide greater sensitivity for assessing the efficacy of therapeutic interventions. In addition, these cognitive capacities can be precisely measured with specific tests that are sensitive to clinical and subclinical changes. The fact that these cognitive measures are considered a proxy of such subclinical changes, closely related with the abnormal functioning of prefrontal-temporal brain networks, is extremely important when testing new therapeutic strategies for mental disability. Currently, a major caveat of clinical trials targeting functional change in DS is that follow-up periods tend to be too short (less than 12 months on average), while improvements in complex functional skills in DS require longer periods (Costa, 2011; Boada et al., 2012) We agree with this view but suggest that subclinical cognitive gains related to positive pharmacological and/or behavioral interventions in DS may be sufficient for a mild, but significant, impact on everyday life functioning, similar to what we can expect in other pathological conditions such as AD (Insel et al., 2013). Studies with extended follow-up periods under active treatment are needed to probe our hypotheses and ensure the validity of the proposed linkages as clinically meaningful for estimating functional change in interventional studies.

\section{Limitations}

Several limitations should be considered when interpreting the results of our study. First, the neurocognitive assessment tools we employed may have influenced the DS cognitive profile observed. The majority of the tests included in our TESDAD battery are, nevertheless, recognized as valid and feasible for tracking cognitive deficits in pathological conditions (Ersche et al., 2012; Juncos-Rabadán et al., 2014), they are well standardized and extensively normalized, and acceptable for DS participants with mild to moderate mental disability (Devenny et al., 2002; Ball et al., 2008; De la Torre et al., 2014). Floor effects were observed for the verbal and visual backward span and mental flexibility tasks, whereas ceiling effects where shown in a few episodic memory variables and in the response inhibition test regarding task accuracy but not for time of response. These limitations were found mainly in specific tests developed for mentally disabled individuals (Weigl, Cats and Dogs and CRT). Although, these findings suggest that these tasks could be replaced, we can 
still consider them suitable for the assessment of the selected population due that these were not found for all variables in each of the mentioned tests (e.g., free recall measures in the CRT), or provide an affordable evaluation of high-order executive capacities in intellectual disability (e.g., Weigl). One of the few commonly used cognitive batteries is the Arizona Battery (ACTB), developed for school age children and young adults with DS (age range 7-30 years), employing the mentalage matched procedure (Edgin et al., 2010a). The principal differences between the ACTB and the TESDAD battery are that TESDAD allows a more thorough, direct cognitive assessment of the main mnemonic and executive components with language being a key domain, whereas ACTB includes a deeper assessment of executive-behavioral dysfunction using questionnaires for parents. In addition, the TESDAD was also designed to be sensitive to mild cognitive impairment, making this tool potentially valid for capturing deterioration in the prodromal stage. Another limitation is that the TESDAD only explores "cool-cognitive functions," whereas "hot-cognitive processing" involving emotional, motivational, and rewarding aspects are omitted. We focused our assessment on cool-conscious high reasoning processes, in particular on executive and mnemonic processing supported by the hippocampus and frontal cortices, because preclinical and clinical evidence consider those to be critical targets for therapeutic intervention in DS. Nonetheless, the TESDAD Battery should undergo further modifications to integrate new feedback provided by future preclinical and clinical evidence. Another drawback is that IQ estimation within the lowest range (IQ < 40) could not be exactly determined with the K-BIT. In addition, the fact that the Kidscreen-27 questionnaire was designed for assessing younger individuals (8-18 years of age), may have partly compromised its sensitivity for determining QoL perception in young adults. The lack of an overall composite score integrating cognitive and functional outcomes is another important limitation, ongoing issue for the TESDAD battery. This comprehensive score would be a valuable asset for globally evaluating treatment effects in longitudinal studies. Finally, the lack of a test-retest reliability assessment of the overall battery is another important drawback. Nonetheless, the selection of tests was based upon previous reliability studies carried for each of these tools (Strauss et al., 2006).

\section{Conclusion}

In summary, the TESDAD battery is a useful tool for a standardized neurocognitive assessment of DS in clinical trials. The most relevant features of this battery include a chronological age-matched approach, high sensitivity for detecting mild to moderate cognitive deficits, and a strong relationship to clinically relevant functional measures. These features make the battery suitable for capturing changes derived from therapy which allow its efficacy to be established.

\section{Members of the TESDAD Study Group}

Aida Cuenca-Royo, Hospital del Mar Medical Research Institute, Barcelona, Spain, Neuropsychologist, Site Investigator;
Alessandro Principe, Hospital del Mar Medical Research Institute, Barcelona, Spain, Neurophysiology Section, Site Investigator; Bessy Benejam, Catalan Foundation of Down Syndrome, FCSD, Barcelona, Spain, Neuropsychologist, Site Investigator; Ester Civit, Hospital del Mar Medical Research Institute, Barcelona, Spain, Site Investigator; Gimena Hernandez, Hospital del Mar Medical Research Institute, Barcelona, Spain, Site Investigator; Gonzalo Sánchez-Benavides, Hospital del Mar Medical Research Institute, Barcelona, Spain, Neuropsychologist, Site Investigator; Henri Bléhaut, Jérôme Lejeune Foundation, Paris, France, Site investigator; Iván Dueñas, Hospital del Mar Medical Research Institute, Barcelona, Spain; Jesús Pujol, Neurovoxel, Barcelona, Spain, neurologist/neuroimaging, Site Investigator; Joan Rodríguez, Hospital del Mar Medical Research Institute, Barcelona, Spain, Study Coordinator; Jordi Peña-Casanova, Hospital del Mar Medical Research Institute, Barcelona, Spain, Dementia Section, Site Investigator; Josep $\mathbf{M}^{\mathbf{a}}$ Espadaler, Hospital del Mar Medical Research Institute, Barcelona, Spain, Neurophysiology Section, Site Investigator; Judit Sánchez, Neuropsychlogist, Feskits, Barcelona, Spain, Site Investigator; Katy Trias, Catalan Foundation of Down Syndrome, FCSD, Barcelona, Spain, Site Investigator; Klaus Langohr, Polytechnics University, Barcelona, Spain, Statistician; Laia Roca, Hospital del Mar Medical Research Institute, Barcelona, Spain, Study Manager; Laura Blanco, Hospital del Mar Medical Research Institute, Barcelona, Spain, Neuropsychologist, Site Investigator; Laura del Hoyo, Hospital del Mar Medical Research Institute, Barcelona, Spain, Neuropsychologist, Site Investigator; Laura Xicota, Hospital del Mar Medical Research Institute, Barcelona, Spain, Site Investigator; Magí Farré, Hospital del Mar Medical Research Institute, Barcelona, Spain, co-PI; Mara Dierssen, Centre for Genomic Regulation- CRG of Barcelona, co-PI; Rafael de la Torre, Hospital del Mar Medical Research Institute, Barcelona, Spain, PI; Rut Freixas, Centre for Genomic RegulationCRG of Barcelona, Site Investigator; Sebastià Videla, Catalan Foundation of Down Syndrome, FCSD, Barcelona, Spain, site investigator; Silvina Catuara-Solarz, Centre for Genomic Regulation- CRG of Barcelona, Site Investigator; Susana De Sola, Hospital del Mar Medical Research Institute, Barcelona, Spain, Neuropsychologist, Site Investigator; Valérie Legout, Jérôme Lejeune Foundation, Paris, France, Site Investigator.

\section{Acknowledgments}

This work has been supported by the Jérôme Lejeune Foundation (Paris, France) the Instituto Carlos III (ISCIII/FIS PI11/00744), and Spanish Ministry of Education and Science (SAF2010-16427), Spain. The CIBER de Enfermedades Raras and the CIBER Fisiopatología de la Obesidad y Nutrición are initiatives of the ISCIII. The laboratory of MD is supported by DURSI (2009SGR1313) and the laboratory of RTF by DURSI (2009SGR718). Dr. Susana de Sola is a post-doctoral fellow from the FRAXA Foundation. Laura del Hoyo is recipient of a predoctoral fellowship from ISCIII [FI12/00319]. We wish to thank Fundació Catalana de Síndrome de Down (Barcelona, Spain) for their assistance with recruitment of volunteers and for providing 
information and guidance along the study and to Fundació Privada Espai Salut for the provision of the cognitive stimulation platform FESKITS. Last but not least, we would like to express very special thanks to all participants and their families for their time and efforts.

\section{References}

Abbeduto, L., Pavetto, M., Kesin, E., Weissman, M. D., Karadottir, S., O’Brien, A., et al. (2001). The linguistic and cognitive profile of Down syndrome: evidence from a comparison with fragile X syndrome. Downs. Syndr. Res. Pract. 7, 9-15. doi: 10.3104/reports.109

American Psychiatric Association. (1994). Diagnostic and Statistical Manual of Mental Disorders (DSM-IV), 4th Edn. Washington, DC: American Psychiatric Association.

Ball, S. L., Holland, A. J., Treppner, P., Watson, P. C., and Huppert, F. A. (2008). Executive dysfunction and its association with personality and behaviour changes in the development of Alzheimer's disease in adults with Down syndrome and mild to moderate learning disabilities. Br. J. Clin. Psychol. 47, 1-29. doi: 10.1348/014466507X230967

Beacher, F., Simmons, A., Daly, E., Prasher, V., Adams, C., Margallo-Lana, M. L., et al. (2005). Hippocampal myo-inositol and cognitive ability in adults with Down syndrome: an in vivo proton magnetic resonance spectroscopy study. Arch. Gen. Psychiatry 62, 1360-1365. doi: 10.1001/archpsyc.62. 12.1360

Bisegger, C., Cloetta, B., von Rueden, U., Abel, T., and Ravens-Sieberer, U. (2005). Health-related quality of life: gender differences in childhood and adolescence. Soz. Praventivmed. 50, 281-291. doi: 10.1007/s00038-005-4094-2

Blumenfeld, R. S., Parks, C. M., Yonelinas, A. P., and Ranganath, C. (2011). Putting the pieces together: the role of dorsolateral prefrontal cortex in relational memory encoding. J. Cogn. Neurosci. 23, 257-265. doi: 10.1162/jocn.2010.21459

Boada, R., Hutaff-Lee, C., Schrader, A., Weitzenkamp, D., Benke, T. A., Goldson, E. J., et al. (2012). Antagonism of NMDA receptors as a potential treatment for Down syndrome: a pilot randomized controlled trial. Transl. Psychiatry 2, e141. doi: 10.1038/tp.2012.66

Braver, T. S. (2001). Anterior cingulate cortex and response conflict: effects of frequency, inhibition and errors. Cereb. Cortex 11, 825-836. doi: 10.1093/cercor/11.9.825

Carducci, F., Onorati, P., Condoluci, C., Di Gennaro, G., Quarato, P. P., Pierallini, A., et al. (2013). Whole-brain voxel-based morphometry study of children and adolescents with Down syndrome. Funct. Neurol. 28, 19-28. doi: 10.11138/ FNeur/2013.28.1.019

Choen, J. (1988). Statistical Power Analysis for the Behavioral Sciences, 2nd Edn. Hillsdale: Lawrence Erlbaum Associates.

Contestabile, A., Benfenati, F., and Gasparini, L. (2010). Communication breaksDown: from neurodevelopment defects to cognitive disabilities in Down syndrome. Prog. Neurobiol. 91, 1-22. doi: 10.1016/j.pneurobio.2010.01.003

Costa, A. C. S. (2011). On the promise of pharmacotherapies targeted at cognitive and neurodegenerative components of Down syndrome. Dev. Neurosci. 33, 414-427. doi: 10.1159/000330861

Costanzo, F., Varuzza, C., Menghini, D., Addona, F., Gianesini, T., and Vicari, S. (2013a). Executive functions in intellectual disabilities: a comparison between Williams syndrome and Down syndrome. Res. Dev. Disabil. 34, 1770-1780. doi: 10.1016/j.ridd.2013.01.024

Costanzo, F., Vicari, S., and Carlesimo, G. A. (2013b). Familiarity and recollection in Williams syndrome. Cortex 49, 232-242. doi: 10.1016/j.cortex.2011.06.007

Culbertson, W., and Zillmer, E. (2005). Tower of London Drexel University: 2nd Edn (TOL DX): Technical Manual, 2nd Edn. New York, NY: Multi-Health Systems Inc.

De la Torre, R., De Sola, S., Pons, M., Duchon, A., de Lagran, M. M., Farré, M., et al. (2014). Epigallocatechin-3-gallate, a DYRK1A inhibitor, rescues cognitive deficits in Down syndrome mouse models and in humans. Mol. Nutr. Food Res. 58:278288. doi: $10.1002 / \mathrm{mnfr} .201300325$

\section{Supplementary Material}

The Supplementary Material for this article can be found online at: http://journal.frontiersin.org/article/10.3389/fpsyg. 2015.00708/abstract

Devenny, D. A., Zimmerli, E. J., Kittler, P., and Krinsky-McHale, S. J. (2002). Cued recall in early-stage dementia in adults with Down's syndrome. J. Intellect. Disabil. Res. 46, 472-483. doi: 10.1046/j.1365-2788.2002.00417.x

Edgin, J. O., Mason, G. M., Allman, M. J., Capone, G. T., Deleon, I., Maslen, C., et al. (2010a). Development and validation of the Arizona Cognitive Test Battery for Down syndrome. J. Neurodev. Disord. 2, 149-164. doi: 10.1007/s11689-010-9054-3

Edgin, J. O., Pennington, B. F., and Mervis, C. B. (2010b). Neuropsychological components of intellectual disability: the contributions of immediate, working, and associative memory. J. Intellect. Disabil. Res. 54, 406-417. doi: 10.1111/j.1365-2788.2010.01278.x

Ersche, K. D., Turton, A. J., Chamberlain, S. R., Müller, U., Bullmore, E. T., and Robbins, T. W. (2012). Cognitive dysfunction and anxious-impulsive personality traits are endophenotypes for drug dependence. Am. J. Psychiatry 169, 926-936. doi: 10.1176/appi.ajp.2012.11091421

Ferrer, I., and Gullotta, F. (1990). Down's syndrome and Alzheimer's disease: dendritic spine counts in the hippocampus. Acta Neuropathol. 79, 680-685. doi: 10.1007/BF00294247

Finestack, L. H., and Abbeduto, L. (2010). Expressive language profiles of verbally expressive adolescents and young adults with Down syndrome or fragile X syndrome. J. Speech. Lang. Hear. Res. 53, 1334-1348. doi: 10.1044/10924388(2010/09-0125)

Iacono, T., Torr, J., and Wong, H. Y. (2010). Relationships amongst age, language and related skills in adults with Down syndrome. Res. Dev. Disabil. 31, 568-576. doi: 10.1016/j.ridd.2009.12.009

Insel, T., Cuthbert, B., Garvey, M., Heinssen, R., Pine, D. S., Quinn, K. et al. (2010). Research domain criteria (RDoC): toward a new classification framework for research on mental disorders. Am. J. Psychiatry 167, 748-751. doi: 10.1176/appi.ajp.2010.09091379

Insel, T., Krystal, J., and Ehlers, M. (2013). New drug development for cognitive enhancement in mental health: challenges and opportunities. Neuropharmacology 64, 2-7. doi: 10.1016/j.neuropharm.2012.07.041

Juncos-Rabadán, O., Facal, D., Pereiro, A. X., and Lojo-Seoane, C. (2014). Visual memory profiling with CANTAB in mild cognitive impairment (MCI) subtypes. Int. J. Geriatr. Psychiatry 29, 1040-1048. doi: 10.1002/ gps.4095

Khoshnood, B., Greenlees, R., Loane, M., Dolk, H., Committee, E. P. M., and Group, E. W. (2011). Paper 2: EUROCAT public health indicators for congenital anomalies in Europe. Birth Defects Res. A Clin. Mol. Teratol. 91(Suppl. 1), S16-S22. doi: 10.1002/bdra.20776

Krasuski, J. S., Alexander, G. E., Horwitz, B., Rapoport, S. I., and Schapiro, M. B. (2002). Relation of medial temporal lobe volumes to age and memory function in nondemented adults with Down's syndrome: implications for the prodromal phase of Alzheimer's disease. Am. J. Psychiatry 159, 74-81. doi: 10.1176/appi.ajp.159.1.74

Lanfranchi, S., Cornoldi, C., and Vianello, R. (2004). Verbal and visuospatial working memory deficits in children with Down syndrome. Am. J. Ment. Retard. 109, 456-466. doi: 10.1352/0895-8017(2004)109<456:VAVWMD $>2$. $0 . \mathrm{CO} ; 2$

Lanfranchi, S., Jerman, O., Dal Pont, E., Alberti, A., and Vianello, R. (2010). Executive function in adolescents with Down Syndrome. J. Intellect. Disabil. Res. 54, 308-319. doi: 10.1111/j.1365-2788.2010.01262.x

Laws, G., and Bishop, D. V. M. (2004). Verbal deficits in Down's syndrome and specific language impairment: a comparison. Int. J. Lang. Commun. Disord. 39, 423-451. doi: 10.1080/13682820410001681207

Lott, I. T., and Dierssen, M. (2010). Cognitive deficits and associated neurological complications in individuals with Down's syndrome. Lancet Neurol. 9, 623-633. doi: 10.1016/S1474-4422(10)70112-5 
Lund, J. (1988). Psychiatric aspects of Down's syndrome. Acta Psychiatr. Scand. 78, 369-374. doi: 10.1111/j.1600-0447.1988.tb06350.x

Määttä, T., Tervo-Määttä, T., Taanila, A., Kaski, M., and Iivanainen, M. (2006). Mental health, behaviour and intellectual abilities of people with Down syndrome. Downs. Syndr. Res. Pract. 11, 37-43. doi: 10.3104/ reports.313

Megarbane, A., Ravel, A., Mircher, C., Sturtz, F., Grattau, Y., Rethore, M. O., et al. (2009). The 50th anniversary of the discovery of trisomy 21 : the past, present, and future of research and treatment of Down syndrome. Genet. Med. 11, 611-616. doi: 10.1097/GIM.0b013e3181b2e34c

Michel, G., Bisegger, C., Fuhr, D. C., and Abel, T. (2009). Age and gender differences in health-related quality of life of children and adolescents in Europe: a multilevel analysis. Qual. Life Res. 18, 1147-1157. doi: 10.1007/s11136-009-9538-3

Næss, K.-A. B., Lyster, S.-A. H., Hulme, C., and Melby-Lervåg, M. (2011). Language and verbal short-term memory skills in children with Down syndrome: a meta-analytic review. Res. Dev. Disabil. 32, 2225-2234. doi: 10.1016/j.ridd.2011.05.014

Peña-Casanova, J., Casals-Coll, M., Quintana, M., Sánchez-Benavides, G., Rognoni, T., Calvo, L., et al. (2012). [Spanish normative studies in a young adult population (NEURONORMA young adults Project): methods and characteristics of the sample]. Neurologia 27, 253-260. doi: 10.1016/j.nrl.2011.12.019

Pennington, B. F., Moon, J., Edgin, J., Stedron, J., and Nadel, L. (2003). The neuropsychology of Down syndrome: evidence for hippocampal dysfunction. Child Dev. 74, 75-93. doi: 10.1111/1467-8624.00522

Raz, N., Torres, I. J., Briggs, S. D., Spencer, W. D., Thornton, A. E., Loken, W. J., et al. (1995). Selective neuroanatomic abnormalities in Down's syndrome and their cognitive correlates: evidence from MRI morphometry. Neurology 45, 356-366. doi: 10.1212/WNL.45.2.356

Robbins, T. W., James, A., Owen, A. M., Sahakian, B. J., McInnes, L., and Rabbitt, P. M. A. (1997). "A neural systems approach to the cognitive psychology of ageing using the CANTAB battery:Studies with CANTAB on a large sample of the normal elderly population," in Methodology of Frontal and Executive Function, ed. P. Rabbitt, 215-238.

Robbins, T. W., James, M., Owen, A. M., Sahakian, B. J., Lawrence, A. D., McInnes, L., et al. (1998). A study of performance on tests from the CANTAB battery sensitive to frontal lobe dysfunction in a large sample of normal volunteers: implications for theories of executive functioning and cognitive aging. J. Int. Neuropsychol. Soc. 4, 474-490. doi: 10.1017/s1355617798455073

Robbins, T. W., and Sahakian, B. (1996). Cambridge Neuropsychological Test Automated Battery. Available online at: http://www.cambridgecognition.com/ technology
Rowe, J., Lavender, A., and Turk, V. (2006). Cognitive executive function in Down's syndrome. Br. J. Clin. Psychol. 45, 5-17. doi: 10.1348/014466505X29594

Strauss, E., Sherman, E. M. S., and Spreen, O. (2006). A Compendium of Neuropsychological Tests: Administration, Norms, and Commentary. New York, NY: Oxford University Press

Takashima, S., Iida, K., Mito, T., and Arima, M. (1994). Dendritic and histochemical development and ageing in patients with Down's syndrome. J. Intellect. Disabil. Res. 38(Pt 3), 265-273. doi: 10.1111/j.1365-2788.1994. tb00394.x

Takeuchi, H., Taki, Y., Nouchi, R., Hashizume, H., Sassa, Y., Sekiguchi, A., et al. (2014). Anatomical correlates of quality of life: evidence from voxel-based morphometry. Hum. Brain Mapp. 35, 1834-1846. doi: 10.1002/hbm.22294

Teipel, S. J., Alexander, G. E., Schapiro, M. B., Moller, H. J., Rapoport, S. I., and Hampel, H. (2004). Age-related cortical grey matter reductions in nondemented Down's syndrome adults determined by MRI with voxel-based morphometry. Brain 127, 811-824. doi: 10.1093/brain/awh101

Torsheim, T., Ravens-Sieberer, U., Hetland, J., Välimaa, R., Danielson, M., and Overpeck, M. (2006). Cross-national variation of gender differences in adolescent subjective health in Europe and North America. Soc. Sci. Med. 62, 815-827. doi: 10.1016/j.socscimed.2005.06.047

Vicari, S. (2006). Motor development and neuropsychological patterns in persons with Down syndrome. Behav. Genet. 36, 355-364. doi: 10.1007/s10519-0069057-8

Wager, T. D., and Smith, E. E. (2003). Neuroimaging studies of working memory: a meta-analysis. Cogn. Affect. Behav. Neurosci. 3, 255-274. doi: 10.3758/CABN.3.4.255

White, N. S., Alkire, M. T., and Haier, R. J. (2003). A voxel-based morphometric study of nondemented adults with Down Syndrome. Neuroimage 20, 393-403. doi: $10.1016 /$ S1053-8119(03)00273-8

Conflict of Interest Statement: The authors declare that the research was conducted in the absence of any commercial or financial relationships that could be construed as a potential conflict of interest.

Copyright (c) 2015 de Sola, de la Torre, Sánchez-Benavides, Benejam, CuencaRoyo, del Hoyo, Rodríguez, Catuara-Solarz, Sanchez-Gutierrez, Dueñas-Espin, Hernandez, Peña-Casanova, Langohr, Videla, Blehaut, Farre, Dierssen and The TESDAD Study Group. This is an open-access article distributed under the terms of the Creative Commons Attribution License (CC BY). The use, distribution or reproduction in other forums is permitted, provided the original author(s) or licensor are credited and that the original publication in this journal is cited, in accordance with accepted academic practice. No use, distribution or reproduction is permitted which does not comply with these terms. 